\title{
Blenda de Náilon-6,6/Quitosana como Adsorvente de Corantes Ácidos para Reutilização das Soluções de Corantes Tratadas em Tingimentos de Poliamida
}

Ivonete 0. Barcellos, Jürgen Andreaus, Ana M. Battisti, Josélia K. Borges Departamento de Química, FURB

\begin{abstract}
Resumo: A água é usada na indústria têxtil como veículo para os produtos químicos em geral e corantes utilizados no processo de tingimento e beneficiamento de fibras. Neste trabalho estudou-se a reutilização de rejeitos líquidos de tingimentos de tecidos de náilon 6,6 (PA 66), tratados pelo processo de adsorção, com uma blenda de PA 6,6/quitosana (80/20), na forma de flocos. Para a produção de rejeitos líquidos, realizaram-se tingimentos de tecidos de PA 66 com os corantes ácidos Yellow Erionyl RXL, Red Erionyl A-3B e Navy Blue Erionyl R. A eficiência da remoção da cor variou entre 97-98\%, com exceção dos rejeitos dos tingimentos com o corante Yellow Erionyl RXL, onde se atingiu apenas eficiências de 65 e $72 \%$ para os rejeitos com e sem auxiliares têxteis, respectivamente. A reutilização dos rejeitos tratados estudou-se em tingimentos de tecidos de malha de poliamida 6,6 com os mesmos corantes. Os valores de $\Delta \mathrm{E}$ (diferença de cor referente a tingimento padrão com água destilada) de tingimentos em cores claras e médias, variaram de 0,24 a 1,05 (para os rejeitos de monocromia) e 0,71 a 1,07 (para os rejeitos de tricromia), e são compatíveis com os padrões industriais $(\Delta \mathrm{E} \leq 1,1)$. Conclui-se que a reutilização dos banhos de tingimento tratados, dentro das condições aqui testadas, é possível, porém com algumas restrições para cores com predominância do amarelo.
\end{abstract}

Palavras-chave: Blenda polyamide 6,6/quitosana, corantes ácidos, reutilização de efluentes têxteis.

\section{Nylon 6.6/Chitosan Blend as Adsorbent of Acid Dyes for the Reuse of Treated Wastewater in Polyamide Dyeing}

\begin{abstract}
Water is used in the textile industry, mainly, as vehicle for chemicals and dyes used in the dyeing and finishing processes of textile fibers. In this work we studied the reuse of wastewater generated in the dyeing of nylon 6.6 (PA6.6) fabrics and treated by adsorption process with nylon 6.6/chitosan (80/20) blend flakes was studied. To produce the wastewater PA 6.6 fabrics were dyed with the acid dyes Yellow Erionyl RXL, Red Erionyl A-3B and Navy Blue Erionyl R. The efficiency in color removal of the adsorption process varied between 97-98\%, with exception of the effluents from Yellow Erionyl RXL dyeing, where only efficiencies of $65 \%$ (wastewater with auxiliaries) and $72 \%$ (without auxiliaries) were obtained. The reuse of the treated wastewater was studied in dyeing of knitted nylon 6.6 fabrics with the same dyes. $\Delta \mathrm{E}$ values (color difference relative to a standard dyeing with distilled water) of the dyeings with light and medium colors varied from 0.24 to 1.05 for the wastewater of monochrome dyeing, and from 0.71 to 1.07 for the wastewater of trichrome dyeing and are compatible with industrial standards $(\Delta \mathrm{E} \leq 1.1)$. It could be concluded that the reuse of treated wastewater from polyamide dyeing under the tested conditions is feasible, although with some restrictions for yellow especially.
\end{abstract}

Keywords: Polyamide 6.6/chitosan blend, acid dyes, wastewater treatment, recycling.

\section{Introdução}

O Estado de Santa Catarina possui um parque fabril dos mais avançados da América, que se destaca no cenário nacional de produção de têxteis. Concentra-se no Vale do Rio Itajaí, basicamente na Bacia do Rio Itajaí-Açu, onde se encontram 75 indústrias, das quais 36 são têxteis, sendo responsáveis por $10 \%$ do faturamento total dos têxteis nacionais e $30 \%$ de total de produtos exportados por toda cadeia têxtil brasileira. A importância desse segmento industrial no Estado chama a atenção quanto aos aspectos ambientais relacionados com esta atividade. Observa-se que as indústrias têm aumentado sua preocupação no que diz respeito à pos- sibilidade de reutilização dos banhos de descarte, direta ou indiretamente, procurando utilizar o mínimo de tratamento possível, de forma a se viabilizar a reutilização sem afetar a qualidade do produto final ou aumentar excessivamente o custo do processo. Assim, a água na indústria têxtil já está sendo avaliada como um componente a mais nas planilhas de custo das empresas e não somente como um veículo no processo de tingimento ${ }^{[1]}$.

As técnicas de adsorção têm se baseado na remoção do corante principalmente empregando carvão ativo. Além deste se encontram na literatura estudos com outros materiais como bauxita, sílica-gel, vermiculite, derivados de celulose, resinas de troca iônica e fibras naturais entre outros 
adsorventes, e diferentes técnicas de descoloração vem sendo pesquisadas ${ }^{[2-5]}$. Adsorventes alternativos para remoção de cor como cinza do bagaço de cana ${ }^{[6]}$, amido de milho ${ }^{[7]}$, material carbonáceo produzido por tratamento em microondas de grãos de cafét ${ }^{[8]}$ e quitosana ${ }^{[9-12]}$ têm sido estudados. A utilização de blendas contendo quitosana para remoção de corantes de efluentes têxteis, visando à reutilização dos mesmos em processos de tingimento, é um método relativamente novo e com poucas referências anteriores ${ }^{[9,13,14]}$. Min \& $\operatorname{Kim}^{[14]}$ prepararam um compósito fibrilar de poliacrilonitrila (PAN) e quitosana formado pela mistura de PAN/quitosana, usando uma certa quantidade de ácido acético diluído, como plastificante. A fibra obtida apresentou uma estrutura porosa e fibrilar, a qual pode ser convertida facilmente em flocos pelo processo de floculação. Os flocos da blenda PAN/quitosana mostraram uma afinidade maior pelo corante ácido do que a quitosana pura em pó e o carvão ativado. Considerou-se que esta melhora na capacidade de adsorção do corante foi devido a maior área superficial dos flocos fibrilares de PAN/quitosana. Os autores observaram que a temperatura e o $\mathrm{pH}$ influenciam o comportamento de adsorção do corante, pois a adsorção é exotérmica e procede por reação tipo ácido-base.

Um aspecto pouco estudado e discutido na maioria dos trabalhos sobre adsorção de corantes é a reutilização dos efluentes tratados, como por exemplo, no trabalho de Quadros ${ }^{[9]}$, quem tratou efluentes industriais contendo corantes reativos com quitosana e com a mistura quitosana/sulfato de alumínio e avaliou a reutilização dos efluentes tratados em diferentes etapas do beneficiamento de tecidos de algodão. Outro exemplo é o trabalho de Battisti ${ }^{[13]}$, quem estudou a adsorção de diferentes corantes ácidos no adsorvente poliamida 66/quitosana, avaliou este sistema também no tratamento de efluentes e estudou a reutilização dos mesmos.

Os corantes ácidos são aniônicos, portadores de um a três grupos sulfônicos $\left(-\mathrm{SO}_{3} \mathrm{H}\right)$ que lhes conferem afinidade com as fibras protéicas e poliamídicas. São solúveis em água e produzidos na forma de sais sódicos. Quanto a sua constituição química, sua parte cromófora possui uma base azóica, antraquinônica, ou são derivados da sulfonação de trifenilmetano, de azina e de xanteno, ou ainda podem apresentar outros grupos, como ftalocianina, indigóide, nitro, nitroso ou quinolina $^{[15]}$. O grupo sulfônico é um forte eletrólito, e está completamente dissociado em $\mathrm{pH}$ ácido (5 a 2).

Como exemplos desta classe de corante podemos citar dois dos corantes ácidos utilizados neste trabalho o corante marinho Erionyl R (1) e o amarelo Erionyl RXL (2), conforme estruturas representadas abaixo.

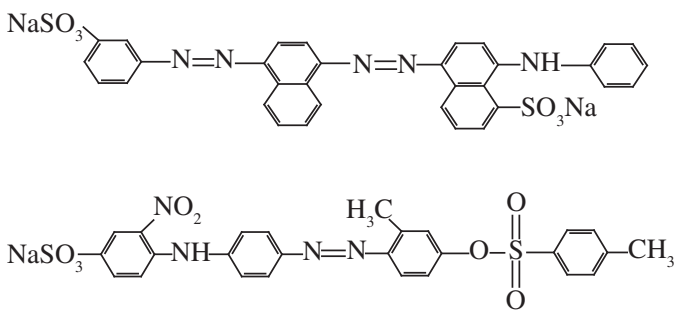

O tingimento de fibras de poliamida ou de fibras protéicas, cujo objetivo é colorir os substratos têxteis de forma homogênea e permanente, requer um meio ácido para protonar os grupos aminas destas fibras e aumentar o esgotamento do banho de tingimento. Quanto maior o número de grupos sulfônicos existentes na molécula do corante, menor o poder de saturação da fibra. Os produtos auxiliares normalmente empregados no tingimento de fibras de poliamida em conjunto com os corantes são umectantes, controladores de $\mathrm{pH}$, igualizantes, eventualmente dispersantes, e agentes antiquebradura, dependendo do tipo de corante ácido e da natureza da fibra utilizada ${ }^{[16,17]}$. O tingimento é uma modificação físicoquímica do substrato, de forma que a luz refletida provoque a percepção de cor.

No presente trabalho foram realizados estudos com rejeitos de tingimentos com corantes ácidos produzidos em laboratório. A proposta desta pesquisa foi avaliar o potencial do emprego de uma blenda formada por adsorvente natural o biopolímero quitosana combinado com sintético, fibras de poliamida 6,6 , proveniente de rejeito industrial, para remoção de cor e reutilização das soluções de corantes tratadas nos tingimentos de tecidos de poliamida, para possibilitar estudos posteriores empregando efluente real gerado nas indústrias que produzem artigos de poliamidas.

\section{Experimental}

\section{Preparação dos flocos da blenda fibra poliamida 6,6/ quitosana (80/20)}

Para cada $10 \mathrm{~g}$ de flocos produzidos foram utilizados 8,0 g fibras de poliamida 6,6 (rebarbas de resíduos industriais) e 2,0 g de quitosana em pó (grau de desacetilação 88,55\%; massa molar 105263,11 g. $\left.\mathrm{mol}^{-1}\right)^{[9]}$. Estes dois polímeros foram dissolvidos separadamente em ácido fórmico $85-88 \%(20 \% \mathrm{~m} / \mathrm{V})$ sob agitação em uma placa de aquecimento durante 5 horas a temperatura ambiente. Após este período, ambas as soluções foram misturadas mantendo-se sob agitação por 24 horas, a temperatura ambiente, para perfeita homogeinização das soluções. A mistura foi colocada em um equalizador e gotejou-se esta solução de polímeros em uma solução de $\mathrm{NaOH} 2$ mol.L $\mathrm{L}^{-1}$, para obtenção dos flocos da blenda de poliamida 6,6/quitosana (80/20). Em seguida, os flocos formados foram lavados com água destilada até a neutralização dos mesmos e secos em estufa à vácuo mantendose a $100{ }^{\circ} \mathrm{C}$ até massa constante.

\section{Produção de rejeitos de tingimento contendo corantes ácidos}

Para gerar efluentes sintéticos, realizaram-se tingimentos em tecidos de malha poliamida $6,6100 \%$, com os corantes ácidos vermelho Erionyl A-3B (estrutura não publicada), amarelo Erionyl RXL (2) e marinho Erionyl R (1) na presença e ausência de auxiliares têxteis (igualizante e sulfato de amônio) conforme receita na Tabela 1. Os banhos de tingimento foram preparados com monocromias (um único co- 
Tabela 1. Receitas dos tingimentos para produção de rejeitos líquidos de monocromia (Mon) e tricromia (Tri).

\begin{tabular}{|c|c|c|c|c|c|c|c|c|c|c|c|c|}
\hline \multirow[t]{3}{*}{ Banhos de tingimento } & \multicolumn{6}{|c|}{ Com auxiliares } & \multicolumn{6}{|c|}{ Sem auxiliares } \\
\hline & \multicolumn{2}{|c|}{ Vermelho } & \multicolumn{2}{|c|}{ Amarelo } & \multicolumn{2}{|c|}{ Marinho } & \multicolumn{2}{|c|}{ Vermelho } & \multicolumn{2}{|c|}{ Amarelo } & \multicolumn{2}{|c|}{ Marinho } \\
\hline & Mon & Tri & Mon & Tri & Mon & Tri & Mon & Tri & Mon & Tri & Mon & Tri \\
\hline Vermelho Erionyl A-3B (\% spm) & 3 & 2 & - & 1 & - & 1 & 3 & 2 & - & 1 & - & 1 \\
\hline Amarelo Erionyl RXL (\% spm) & - & 1 & 4 & 2 & - & 1 & - & 1 & 4 & 2 & - & 1 \\
\hline Marinho Erionyl R (\% spm) & - & 1 & - & 1 & 4 & 2 & - & 1 & - & 1 & 4 & 2 \\
\hline Igualizante P.A $(\% \mathrm{~m} / \mathrm{V})$ & 1 & 1 & 1 & 1 & 1 & 1 & - & - & - & - & - & - \\
\hline Sulfato de amônio P.A $(\%$ m/V) & 3 & 3 & 3 & 3 & 3 & 3 & - & - & - & - & - & - \\
\hline Ácido acético glacial (g.L $\left.\mathrm{L}^{-1}\right)$ & 2 & 2 & 2 & 2 & 2 & 2 & 2 & 2 & 2 & 2 & 2 & 2 \\
\hline$\lambda \max (n m)$ & 521 & 551 & 435 & 555 & 565 & 558 & 521 & 551 & 435 & 555 & 565 & 558 \\
\hline
\end{tabular}

spm peso do produto sobre peso de material têxtil (\%).

rante em cada banho) e tricomias (três corantes em cada banho). Os banhos de tingimento foram preparados conforme Tabela 1, utilizando 3 ou $4 \%$ de corante sobre peso material (spm), ou seja, 3 ou $4 \mathrm{~g}$ de corantes para $100 \mathrm{~g}$ tecido. A relação de banho do tingimento foi 1:20 (1 g de tecido para cada $20 \mathrm{~mL}$ de água). Os tingimentos foram realizados em aparelho de tingimento (Tubotest Kimak), iniciando-se na temperatura de $30{ }^{\circ} \mathrm{C}$ e elevando-se para $95{ }^{\circ} \mathrm{C}$ em 30 minutos, mantendo-se nesta temperatura por 60 minutos, segundo indicação do fabricante do corante (Ciba). Ao final do tingimento os rejeitos líquidos foram guardados para tratamentos posteriores, visando à remoção da cor.

\section{Tratamento dos rejeitos líquidos}

Considerando-se resultados de estudos cinéticos anteriores ${ }^{[13]}$, os rejeitos líquidos dos tingimentos foram tratados com a blenda poliamida 6,6/quitosana (80/20). Os tratamentos foram realizados em erlenmeyer a $40{ }^{\circ} \mathrm{C}$ (banho termostatizado) sob agitação constante $(150 \mathrm{rpm})$ por 180 minutos. Após a filtração a vácuo, mediu-se a absorbância dos líquidos em espectrofotômetro UV-visível (Shimadzu UV-1601PC) nos respectivos comprimentos de onda de máxima absorção $\left(\lambda_{\max }\right)$ para cada solução, conforme indicado na Tabela 1.

A partir dos valores de absorbância dos banhos de tingimento antes e depois do tratamento determinou-se de acordo com a Equação 1 a eficiência do tratamento baseado na remoção do corante em \%.

$$
\text { Remoção da cor }(\%)=
$$

Absorbância inicial - Absorbância final x 100

$$
\text { Absorbância inicial }
$$

\section{Reutilização dos rejeitos líquidos tratados}

Os rejeitos líquidos tratados foram utilizados em tingimentos de tecidos de malha 100\% poliamida 6,6 (Rhodia Poliamida S/A, São Paulo, Brasil), em escala laboratorial, em aparelho de tingimento (KIMAK Tubotest, Knihs, Brusque), iniciando-se na temperatura de $30{ }^{\circ} \mathrm{C}$, elevando-se para $95{ }^{\circ} \mathrm{C}$ em 30 minutos e mantendo-se nesta temperatura por 60 minutos. Os tingimentos foram realizados em cinco cores nas tonalidades clara, média e escura, com e sem auxiliares de acordo com as receitas descritas abaixo (1 a 5). A relação de banho foi 1:10 ( $1 \mathrm{~g}$ de tecido para cada $10 \mathrm{~mL}$ de água). Para fins comparativos foi realizado um tingimento padrão utilizando água destilada. Após os tingimentos, as amostras foram lavadas com água corrente e secas a temperatura ambiente. Todos os tingimentos foram realizados em triplicata.

\section{Receitas de tingimento}

Todos os valores em $\%$ se referem ao peso do produto relativo ao peso do material têxtil (spm):

- Cor clara (bege): amarelo Erionyl RXL $(0,15 \%)$, vermelho Erionyl A-3B (0,02\%), marinho Erionyl R $(0,006 \%)$, igualizante $(2 \%)$, sulfato de amônio P.A $(3 \%)$

- Cor média (kaki): amarelo Erionyl RXL (0,3\%), vermelho Erionyl A-3B (0,08\%), marinho Erionyl R $(0,02 \%)$, igualizante (2\%), sulfato de amônio P.A (3\%);

- Cor média (amarela): amarelo Erionyl RXL (2,0\%), igualizante (2\%), sulfato de amônio P.A (3\%), ácido acético glacial (1 g.L $\left.\mathrm{L}^{-1}\right)$;

- Cor escura (marinho): marinho Erionyl R (2,0\%), igualizante (2\%), sulfato de amônio P.A (3\%), ácido acético glacial $\left(1\right.$ g.L. $\left.\mathrm{L}^{-1}\right)$; e

- Cor escura (vermelho): vermelho Erionyl A-3B (2,0\%) igualizante (2\%), sulfato de amônio P.A (3\%), ácido acético glacial $\left(1\right.$ g. $\left.\mathrm{L}^{-1}\right)$.

O igualizante usado foi Breviol P.A (Cognis), os corantes ácidos usados foram fornecidos pela Ciba. Todos os outros produtos usados neste estudo eram de qualidade analítica.

Análises das propriedades tintoriais dos tecidos tintos

\section{Determinação dos valores da intensidade colorística e da diferença de cor residual}

Nos tecidos tingidos e secos determinou-se através de medições em espectrofotômetro de remissão (OPTRONIK Gmbh) a refletância e a partir deste valor calculou-se usando a equação de Kubelka-Munk (Equação 2) a intensidade de cor $(\mathrm{K} / \mathrm{S})$. A diferença de cor residual $(\Delta \mathrm{E})$ obteve-se a partir do valor de remissão relativo ao tingimento padrão, re- 
alizado nas mesmas condições com água destilada, usando a Equação 3.

$$
\frac{K}{S}=\frac{(1-R)^{2}}{2 R}
$$

onde $\mathrm{K}=$ medida para absorção da luz pelo corante; $\mathrm{S}=$ medida para absorção da luz pelo substrato; e $\mathrm{R}$ = representa o valor de remissão:

$$
\Delta E=\sqrt{\Delta H+\Delta L+\Delta C}
$$

onde $\Delta \mathrm{H}=$ desvio de tonalidade de cor; $\Delta \mathrm{C}=$ desvio de pureza de cor; e $\Delta \mathrm{L}=$ desvio de luminosidade de cor.

\section{Resultados e Discussão}

\section{Determinação da eficiência dos tratamentos dos rejeitos}

A quitosana vem sendo estudada por seu alto poder de adsorção de corantes, íons metálicos, proteínas e outros ${ }^{[9-12]}$. O comportamento da adsorção da quitosana em soluções ácidas aquosas, se deve no mínimo a dois fatores. Primeiro, o ácido acético, onde ela é dissolvida, é frequentemente utilizado como regulador no processo de tingimento, no qual o $\mathrm{pH}$ da solução do corante é ajustado entre 3-4, e segundo, devido à quantidade elevada dos grupos aminos da quitosana, neste $\mathrm{pH}$, que adsorvem fortemente os ânions do corante por atração eletrostática ${ }^{[18]}$.

A adsorção de um corante ácido sobre a poliamida devese à formacao de ligações iônicas ou interações eletrostáticas entre os grupos aniônicos do corante e os grupos terminais amínicos da poliamida, de caráter catiônico por associação dos íons hidrogênio. Essa reação ocorre na primeira fase do tingimento e acontece continuamente passo a passo depois que as moléculas de corante se difundem na fibra, criando assim um equilíbrio superficial até que o banho de tingimento não seja mais esgotado. A velocidade de difusão na fibra após a formação desse equilíbrio corante-fibra é determinante para a uniformidade do tingimento.

Inicialmente neste estudo foram produzidos rejeitos separados para cada corante ácido (monocromia), para verificar o comportamento de cada corante frente ao tratamento de remoção de cor com o adsorvente poliamida 6,6/quitosana (80/20) e avaliar também a influência dos auxiliares (igualizante, por exemplo) utilizados pelas indústrias têxteis para este tipo de processo.

Posteriormente, produziram-se rejeitos de mistura de corantes através de tingimentos em tricomia, usando concentrações distintas e simulando um efluente real (Tabela 1) para verificar o comportamento frente ao processo de remoção da cor. O esgotamento dos tingimentos para produção de rejeitos variou entre 65 e $99 \%$, em função da afinidade de cada corante para com a fibra de poliamida 6,6 , sendo pouco dependente da presença de auxiliares testados, pois a variação foi de 1 a 5\% no percentual de eficiência. Entretanto, deve-se considerar que apesar dos elevados índices de esgotamento

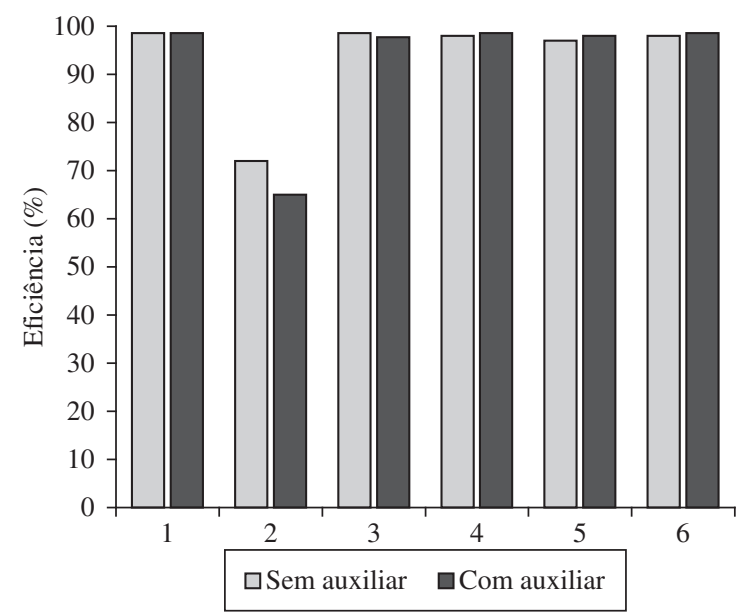

Figura 1. Eficiência na remoção da cor de rejeitos líquidos provenientes de tingimentos dos tecidos $100 \%$ náilon 6,6 com os corantes ácidos vermelho, amarelo (2) e azul marinho (1) em monocromia e tricromia. 1) 3\% vermelho; 2) $4 \%$ amarelo; 3) $4 \%$ marinho; 4) mistura de corantes (vermelho a $2 \%$, marinho e amarelo a $1 \%$ ); 5) mistura de corantes (amarelo a $2 \%$, vermelho e marinho a $1 \%$ ); e 6 ) mistura de corantes (marinho a $2 \%$, amarelo e vermelho a $1 \%$ ).

em alguns casos, a cor dos rejeitos dos tingimentos ainda foi intensa, devido à alta concentração de corante empregada para obtenção de cores escuras o que justifica o tratamento.

A Figura 1 mostra a eficiência do adsorvente estudado na remoção dos corantes dos banhos dos seguintes rejeitos. Pode-se observar que para a maioria dos rejeitos líquidos a eficiência da remocao da cor pelo processo de adsorçao variou entre $97-98 \%$. Apenas com os rejeitos dos tingimentos com o corante amarelo Erionyl RXL obteve-se eficiências inferiores de 65 e $72 \%$ para os rejeitos com e sem auxiliares têxteis, respectivamente. Levando em consideração a remoção de cor atingida nos tratamentos todos os rejeitos tratados, com exceção dos efluentes dos tingimentos com corante amarelo (monocromia), estavam a princípio aptos para serem reutilizados, pois de acordo com trabalhos anteriores ${ }^{[9]}$ é necessário uma remoção de cor superior a 90\%, para não haver interferência na tonalidade dos tingimentos. Estudos detalhado das isotermas de adsorção dos corantes estudados neste trabalho encontram-se na literatura ${ }^{[13]}$, a qual serviu de subsídio no desenvolvimento deste estudo, na escolha das condições de tratamento em termos de tempo de contato, temperatura e concentração de adsorvente.

\section{Determinação de $K / S$ e $\Delta E$ dos tecidos tintos com rejeitos tratados}

Neste estudo, a escolha dos auxiliares levou em conta a afinidade pela fibra e o tipo do corante ácido. No tingimento, os auxiliares (igualizantes (Breviol P.A) e sulfato de amônio) podem agir de diferentes formas. Existem igualizantes que atuam como inibidores, agindo sobre os corantes limitando a sua disponibilidade de se fixar à fibra, o que resulta num retardamento da fixação do corante e por conseqüência, num efeito de migração mais uniforme. Já, os igualizantes que possuem afinidade pela fibra, em geral possuem molé- 
cula menor que a do corante e se difundem mais facilmente e com maior velocidade no interior da fibra. No processo de tingimento, este igualizante ocupa os pontos de acesso mais livres na fibra antes do corante. Com isso, a fixação do corante é retardada e promovida a sua migração e a uniformização do tingimento ${ }^{[21]}$. Considerando-se os efeitos dos auxiliares nos processos de tingimento, os experimentos foram realizados na ausência e presença destes auxiliares, visando avaliar a possível influência no caso de reutilização da água em novos tingimentos.
As Tabelas 2 e 3 mostram os valores médios das intensidades colorísticas $(\mathrm{K} / \mathrm{S})$ e da diferença de cor $(\Delta \mathrm{E})$, dos tecidos de malha $100 \%$ náilon 6,6 tintos com monocromia e tricromia, nas cores clara, média e escuras, com as soluções tratadas (rejeitos) e também com água destilada para comparativo (padrão). Observa-se que os valores obtidos de $\mathrm{K} / \mathrm{S}$ estão muito próximos entre si para a maioria das cores testadas, comparados ao padrão, o que indica que não há diferenças significativas na intensidade da cor dos tecidos tintos com água de diferente procedência e principalmente não

Tabela 2. Valores obtidos para K/S e $\Delta \mathrm{E}$ nos tecidos tintos com diferentes soluções de corantes, na ausência e presença de auxiliares, com rejeitos líquidos (de tingimentos de monocromia) tratados e com água destilada.

\begin{tabular}{|c|c|c|c|c|c|c|}
\hline \multirow{3}{*}{$\begin{array}{c}\text { Rejeito de } \\
\text { tingimento } \\
\text { tratado }(\%)\end{array}$} & \multirow[t]{3}{*}{ Cores } & \multirow{3}{*}{$\begin{array}{c}\text { Água destilada } \\
\text { K/S } \\
\text { Com aux. } \\
\end{array}$} & \multicolumn{4}{|c|}{ Rejeito tratado } \\
\hline & & & \multicolumn{2}{|c|}{$\mathrm{K} / \mathrm{S}$} & \multicolumn{2}{|c|}{$\Delta \mathbf{E}$} \\
\hline & & & Com aux. & Sem aux. & Com aux. & Sem aux. \\
\hline \multirow{4}{*}{ Vermelho - 3} & Caqui & 6,496 & 6,719 & 6,559 & 0,240 & 0,510 \\
\hline & Amarela & 31,738 & 28,957 & 30,093 & 0,810 & 0,730 \\
\hline & Vermelha & 30,118 & 34,923 & 30,755 & 0,420 & 0,610 \\
\hline & Marinho & 39,446 & 36,270 & 37,276 & 0,390 & 0,430 \\
\hline \multirow[t]{5}{*}{ Amarelo - 4} & Bege & 4,089 & 3,998 & 4,327 & 0,810 & 0,760 \\
\hline & Caqui & 7,551 & 7,666 & 7,784 & 0,310 & 0,710 \\
\hline & Amarela & 31,950 & 32,445 & 35,021 & 0,280 & 0,280 \\
\hline & Vermelha & 36,249 & 35,925 & 36,748 & 0,620 & 0,380 \\
\hline & Marinho & 41,079 & 38,926 & 44,970 & 0,640 & 0,230 \\
\hline \multirow[t]{5}{*}{ Marinho - 4} & Bege & 4,511 & 4,4853 & 4,529 & 0,820 & 1,050 \\
\hline & Caqui & 12,085 & 8,3996 & 8,067 & 0,370 & 0,290 \\
\hline & Amarela & 28,293 & 30,801 & 34,726 & $1,740 *$ & $2,530 *$ \\
\hline & Vermelha & 36,847 & 35,836 & 40,726 & 0,370 & $1,650 *$ \\
\hline & Marinho & 41,210 & 39,171 & 42,978 & 0,840 & $1,140 *$ \\
\hline
\end{tabular}

*Não seria aprovado pela indústria $(>1,1)$.

Tabela 3. Valores obtidos para K/S e $\Delta \mathrm{E}$ nos tecidos tintos com diferentes soluções de corantes, na ausência e presença de auxiliares, com rejeitos líquidos (de tingimentos de tricromia) tratados e com água destilada.

\begin{tabular}{|c|c|c|c|c|c|c|}
\hline \multirow{3}{*}{$\begin{array}{c}\text { Rejeito de } \\
\text { tingimento } \\
\text { tratado }(\%)\end{array}$} & \multirow[t]{3}{*}{ Cores } & \multirow{3}{*}{$\begin{array}{c}\text { Água destilada } \\
\text { K/S } \\
\text { Com aux. }\end{array}$} & \multicolumn{4}{|c|}{ Rejeito tratado } \\
\hline & & & \multicolumn{2}{|c|}{$\mathrm{K} / \mathrm{S}$} & \multicolumn{2}{|c|}{$\Delta \mathbf{E}$} \\
\hline & & & Com aux. & Sem aux. & Com aux. & Sem aux. \\
\hline Vermelho - 2 & Caqui & 6,029 & 6,422 & 6,557 & 1,060 & 1,040 \\
\hline Marinho - 1 & Amarela* & 34,437 & 35,570 & 37,782 & $1,150 *$ & $1,400 *$ \\
\hline \multirow{2}{*}{ Amarelo - 1} & Marinho & 43,905 & 43,133 & 38,481 & 0,910 & 1,230 \\
\hline & Bege & 4,554 & 4,721 & 4,348 & 0,990 & 1,080 \\
\hline Vermelho - 1 & Caqui & 7,084 & 7,551 & 7,455 & 1,040 & 0,750 \\
\hline Marinho - 1 & Amarela* & 34,899 & 37,635 & 35,694 & $1,710^{*}$ & $1,360 *$ \\
\hline \multirow[t]{3}{*}{ Amarelo - 2} & Vermelha & 38,483 & 40,241 & 39,854 & 1,120 & 0,780 \\
\hline & Marinho & 44,127 & 43,605 & 40,941 & 0,730 & 1,020 \\
\hline & Bege & 4,832 & 4,348 & 4,393 & 0,910 & 1,020 \\
\hline Vermelho - 1 & Caqui & 9,222 & 7,276 & 6,231 & 0,710 & 1,000 \\
\hline Marinho - 2 & Amarela* & 34,536 & 36,413 & 35,722 & 1,080 & 0,520 \\
\hline \multirow[t]{2}{*}{ Amarelo - 1} & Vermelha & 37,519 & 37,477 & 40,318 & 0,280 & 0,520 \\
\hline & Marinho & 43,381 & 46,886 & 44,560 & 0,350 & 0,850 \\
\hline
\end{tabular}

*Não seria aprovado pela indústria $(>1,1)$. 
há desvios significantes referente ao tingimento padrão com água destilada. $\mathrm{O}$ valor de $\Delta \mathrm{E}$ é um indicativo de reprodutibilidade da cor. Os valores limites para o desvio de cor $\Delta \mathrm{E}$, normalmente usados nas empresas têxteis para a liberação da cor no processo de tingimento, variam de 0,3 a 1,1 conforme exigência de cada cliente. Observa-se que a maioria dos tingimentos realizados com os rejeitos líquidos tratados apresentou um valor de $\Delta \mathrm{E}$ abaixo de 1,0 sinalizando o potencial da utilização deste método de tratamento, visando a reutilização do rejeito tratado.

A maioria dos valores de $\Delta \mathrm{E}$ obtidos estava dentro da faixa de valores aceitáveis tanto para os rejeitos de banhos com auxiliares, quanto para os rejeitos de banhos sem auxiliares, portanto estes não interferiram na eficiência do tratamento. Este resultado é importante, uma vez que estes auxiliares normalmente estão presentes nos tingimentos industriais convencionais com tecidos de poliamida.

Exceto, para o tingimento na cor amarela com e sem auxiliares utilizando rejeitos tratados da monocromia do azul marinho (Tabela 2) e de duas tricromias (A: $2 \%$ vermelho + $1 \%$ marinho $+1 \%$ amarelo; $\mathrm{B}: 2 \%$ amarelo $+1 \%$ marinho + $1 \%$ vermelho) os valores de $\Delta \mathrm{E}$ estavam acima da faixa de aprovação, ou seja $\Delta \mathrm{E}>1$,1. Este comportamento pode ser explicada pelo fato da remoção da cor por este tratamento ter sido menos eficiente para o corante amarelo como pode ser visto na Figura 1. Assim sendo os rejeitos contendo $100 \%$ de corante amarelo ou tricromias em que este corante estava em maior proporção quando reutilizados não apresentaram uma boa reprodutibilidade da cor. Na literatura encontram-se poucos trabalhos envolvendo tratamento e reutilização de soluções de corantes, sobre tudo rejeitos de tingimento. Gutiérrez e colaboradores ${ }^{[22]}$ propuseram em um estudo a otimização de um tratamento eletroquímico para eliminar a cor de águas residuais de tingimentos em algodão com corantes reativos. Embora sendo outra classe de corante, os valores de $\Delta \mathrm{E}$ obtidos por eles estavam entre 1,18 e 3.08 , ou seja, bem acima dos obtidos em nosso estudo, cujo valor mais alto para tingimentos com corante ácido amarelo Erionyl RXL foi 1,74.

\section{Conclusão}

No tratamento dos rejeitos, provenientes dos tingimentos dos tecidos de náilon 6,6 com corantes ácidos, a blenda náilon 6,6/quitosana 80/20 (flocos) apresentou uma alta afinidade com os corantes ácidos, obtendo-se índices de remoção da cor superior a $95 \%$. A presença dos auxiliares têxteis (igualizante e sulfato) não interferiu na capacidade de adsorção da blenda, pois a eficiência foi praticamente igual para os rejeitos contendo ou não estes auxiliares.

As propriedades tintoriais (K/S e $\Delta \mathrm{E}$ ) dos tecidos tingidos com os rejeitos líquidos tratados foram satisfatórias, principalmente nos tingimentos monocrômicos, não mostrando desvios de cor significativos referente aos tingimentos padrão com água destilada. No caso da reutilização dos rejeitos de tricomias, percebe-se nos resultados de K/S e $\Delta \mathrm{E}$ diferen- ças maiores em alguns casos, sobretudo nos tingimentos com corante amarelo, o que dificultaria para algumas tonalidades o emprego deste método de tratamento. Constatou-se que a reprodutibilidade dos tingimentos é melhor quando se usa rejeito tratado de apenas um corante (monocromia). Quando se reutiliza rejeito tratado de misturas de corantes (tricromia) os tingimentos de tonalidades amareladas são afetadas. Aparentemente, a cor amarela, por ser uma cor mais clara, está sujeita a interferências de resíduos de banho de tingimento.

Os resultados obtidos permitem concluir que a reutilização dos banhos de tingimento dentro das condições de tratamento aqui testadas não serão viáveis para todas as cores, a menos que seja considerado a possibilidade de diluição desta água tratada com água não reciclada, o que sem dúvida ainda estaria gerando uma grande economia de consumo. A viabilidade disto teria que ser avaliado do ponto de vista industrial, visto que, cada indústria trabalha com cartelas de cores específicas. Além do mais, este método de tratamento deve ser testado com efluente real, ou seja, efluentes da ETA que na maioria das empresas contêm misturas de corantes como dispersos e reativos nos casos em que além de artigos de poliamida também são beneficiados artigos com fibras de algodão e poliéster, respectivamente.

\section{Agradecimentos}

Os autores agradecem às empresas Ciba Especialidades Químicas Ltda e Albany International Tecidos Técnicos Ltda pela doação dos corantes e resíduos de poliamida 6,6, respectivamente, a Capes e a Giovana Aparecida Vieira pela assistência nas medições de colorimetria.

\section{Referências Bibliográficas}

1. Twardokus, R. G. \& Souza, A. A. U. - Química Têxtil, 79, p. 32 (2005).

2. Pereira, M. F. R. et al. - Carbon, 41, p.811 (2003).

3. Voncina, D. B. \& Majeen-le-marechal, A. - Dyes and Pigments, 59, p.173 (2003).

4. Wong, Y. C. et al. - Process Biochemistry, 30, p. 1 (2003).

5. Baldissarelli, V. Z. - "Estudo da adsorção do corante reativo preto 5 sobre Carvão Ativado: Caracterização do Adsorvente e Determinação de Parâmetros Cinéticos e Termodinâmicos.” Dissertação Mestrado em Química, Universidade Regional de Blumenau, Brasil, (2006).

6. Gupta, V. K. et al. - Science and Tecnology, 35, (13), p.2097 (2000).

7. Hirata, M. et al. - Journal of Colloid and Interface Science, 254, p. 17 (2002).

8. Singh, K. P. et al. - Industrial and Engineering Chemistry, 42, (9), p.1965 (2003). 
9. Quadros, S. S. - "Tratamento e Reutilização de Efluentes Têxteis Gerados nos Tingimentos de Tecidos de Algodão". Dissertação Mestrado, Universidade Regional de Blumenau, Brasil (2005).

10. Chiou, M. S.; Ho, P. Y. \& Li, H. Y. - Dyes and Pigments, 60, p.69 (2004).

11. Ming-Shen, C.; Pang-Yen, H. \& Hsing-Ya, L. - Dyes and Pigments, 60, p.69 (2004).

12. Chao, A. C. et al. - Bioresource Tecnology, 92, p.157 (2004).

13. Battisti, A. M. - "Estudo da adsorção de corantes ácidos em blendas de poliamida-6,6/quitosana e reutilização das soluções em tingimentos de poliamida" Dissertação Mestrado, Universidade Regional de Blumenau, Brasil (2006).

14. Min, B. G. \& Kim, C. W. - Journal of Applied Polymers Science, 84, p. 2505 (2002).
15. Colour Index; The Society of Dyers and Colourists American Association of textil Chemist and Colourists, $3^{a}$ ed. (1987).

16. Toledo, R. A. S. - Química Têxtil, 74, p.08 ( 2004).

17. Beltrame, L. T. C.; Dantas, T. N. C. \& Neto, A. A. D. Química Nova, 76, p.64 (2004).

18. Valencia, S. A. et al. - The Philippine Agriculture Scientist. 84, p.304 (2001).

19. Zanoni, M. V. B. \& Guaratini, C. C. I. - Química Nova; 01, p.71 (2000).

20. Rosa, J. M. - Química Têxtil, 72, p.26 (2003).

21. Lamberti, S. P. - Química Têxtil, 59, p.57 (2000).

22. Gutiérrez, M. C. et al. - Química Têxtil, 87, p.38, (2007).

Enviado: 06/09/07

Reenviado: 19/12/07

Aceito: $29 / 02 / 08$ 